\title{
Simultaneous removal of particles and dissolved organic matter in floating media filter for surface water treatment
}

\author{
C. Chiemchaisri ${ }^{\mathrm{a}, *}$, S. Passananon ${ }^{\mathrm{a}}$, H. H. Ngo ${ }^{\mathrm{b}}, \mathrm{S}$. Vigneswaran $^{\mathrm{b}}$ \\ ${ }^{a}$ Department of Environmental Engineering/National Center of Excellence for Environmental and Hazardous Waste Management, \\ Faculty of Engineering, Kasetsart University, Bangkok 10900, Thailand \\ Tel.+66(2)5790730; Fax.+66(2)5790730; email: fengccc@ku.ac.th \\ ${ }^{b}$ School of Civil and Environmental Engineering, University of Technology Sydney, NSW 2007, Australia
}

Received 13 May 2009; Accepted 31 August 2009

\begin{abstract}
A B S T R ACT
This research investigated the performance of floating media filter in removing particles and dissolved organic matter from surface water. Pilot-scale study consists of floating plastic media pre-filter connected with either granular activated carbon (GAC) or sponge biological filter (BF) bed. In the floating plastic media filter, coagulation and flocculation processes using poly-aluminum chloride (PACl) as coagulant at an optimum dose of $8 \mathrm{mg} / \mathrm{L}$ helped removing particles from raw water. The floating media filter was operated a filtration rate of $11 \mathrm{~m}^{3} / \mathrm{m}^{2} . \mathrm{h}$ whereas those in GAC and BF units were maintained at $2 \mathrm{~m}^{3} / \mathrm{m}^{2} . h$. Continuous operation for over 120 days gave $98 \%$ and $99 \%$ average removal efficiencies of turbidity and $U_{2}$ in floating media filter in combination with GAC unit whereas and $78 \%$ and $52 \%$ removal efficiencies of turbidity and $\mathrm{UV}_{254}$ removal were obtained in floating media filter in combination with BF. The removal of dissolved organic carbon in GAC and BF units reduced chlorine demand for disinfection by $29 \%$ and $14 \%$. It could also reduce the sum of trihalomethane (THMs) ratio from 1.1 to 0.1 and 0.5 respectively.
\end{abstract}

Keywords: Biological filter; Floating media; Granular activated carbon; Natural organic matter; Water treatment

\section{Introduction}

Conventional water treatment processes, i.e. coagulation, flocculation, sedimentation, filtration and disinfection processes, are applied particularly for the removal of particulate or suspended solids from water. These conventional treatment units are also capable of removing some fraction of small colloidal particles and dissolved organic matter [1]. Recently, the deterioration of raw water qualities and stringent regulations of treated water raise the demand of new treatment processes with high treatment efficiency and reliability. Moreover, they should have smaller footprint and less operating

${ }^{*}$ Corresponding author. cost comparing to the conventional processes. For this purpose, a water treatment system utilizing floating media filter was developed. The system has been successfully applied as a contact-flocculator and filtration units in surface water treatment $[2,3]$. Major advantages of the system were high particle retention capacity with low energy requirement. The floating media filter was applied as a pretreatment of microfiltration (MF) membrane unit for reducing the loading of solid particles and promote the agglomeration of particles to the membrane. Its application helps reducing the fouling in subsequent MF membrane unit when raw water containing high turbidity was treated [4]. The system was found capable of removing substantial amount of natural organic matter through enhanced coagulation process $[5,6]$. 
Beside physico-chemical treatment processes, biological treatment such as biological filter $[7,8]$ or bioreactor systems [9] have been applied to remove dissolved organic matter especially humic substances in the polluted surface water. When biological filter is used, application of granular activated carbon (GAC) as filter media could enhance the removal of dissolved organic carbon through physical adsorption and subsequently biodegradation [10]. The other alternative is applying direct biofiltration with long-term acclimatization of microorganisms to degrade slowly biodegradable organic matter such as humic substances [11]. In this study, two-stage filtration system using floating plastic media filter in combination with GAC and sponge biological filter (BF) was tested in pilot scale using actual raw water from a water treatment plant in Thailand. Simultaneous removal of particles and dissolved organic carbon (DOC) in this filtration system was investigated. This integrated filtration system is developed as the pre-treatment for reducing disinfection by-products (DBPs) formation [10] and membrane fouling [12] in subsequent treatment units.

\section{Methodology}

\subsection{Experimental system}

Pilot scale floating media filtration system as shown in Fig. 1 Two floating plastic media columns with $0.225 \mathrm{~m}$ diameter and $1.20 \mathrm{~m}$ height filled with plastic media (PP bead, $3.6 \mathrm{~mm}$ diameter) of $1.0 \mathrm{~m}$ bed height were used for first stage treatment. The effluent from the pre-treatment units was treated either in sponge biofilter (BF) or in granular activated carbon (GAC) column, both with $1.0 \mathrm{~m}$ bed height. Commercial grade sponge media $\left(20^{*} 20^{*} 20 \mathrm{~mm}\right.$ size, $232.6 \mathrm{~m}^{2} / \mathrm{m}^{3}$

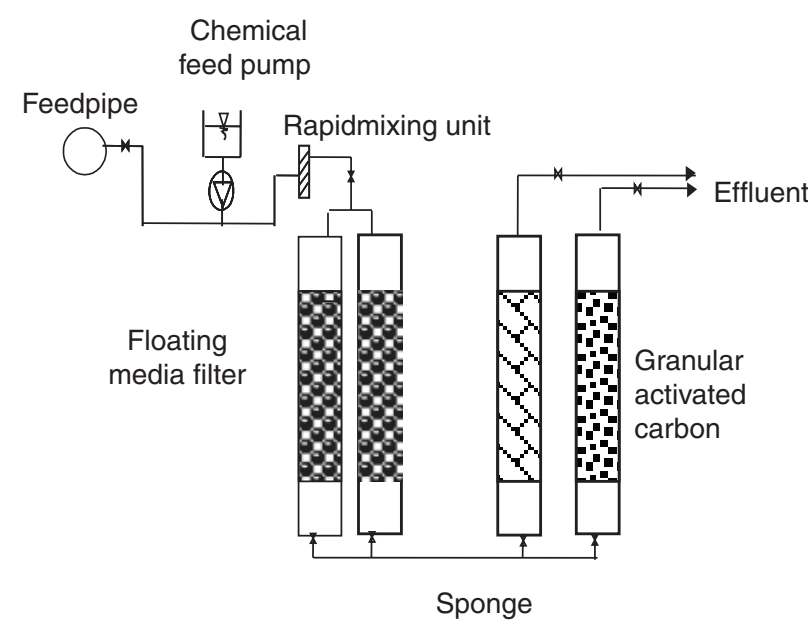

Fig. 1. Schematic of pilot plant. surface area, $14 \mathrm{~kg} / \mathrm{m}^{3}$ density, $46 \%$ porosity) and GAC (1.18-2.36 mm size, $1050 \mathrm{~m}^{2} / \mathrm{g}$ surface area, $470 \mathrm{~kg} / \mathrm{m}^{3}$ density)were used in post treatment units. Raw water was supplied from the feed pipe of Bangkhen water treatment plant, Bangkok Metropolitan Waterworks. Poly-aluminum chloride (PACl) was fed as coagulant to the raw water at an optimum dose of $8.0 \mathrm{mg} / \mathrm{L}$ that was pre-determined from standard jar test. The filtration rate in plastic media filter was kept constant at $11 \mathrm{~m}^{3} / \mathrm{m}^{2}$.h whereas those in BF and GAC columns were set equally at $2.0 \mathrm{~m}^{3} / \mathrm{m}^{2} . \mathrm{h}$. Air and water backwashing was periodically performed when the breakthrough of particles was observed in the experimental system.

\subsection{Raw water characteristics}

Raw water characteristics of Bangkhen water treatment plant monitored over 120 days during the experiment are shown in Table 1. The raw water was delivered from Chaopraya river water, major water supply source of Bangkok Metropolitan. As shown in Table 1, it was found that most of the water quality parameters are fluctuated within a narrow range, exhibit typical variation in dry period during which the experiment was conducted. The raw water contained moderate turbidity level of 38 NTU. To represent dissolved organic matter, average dissolved organic carbon (DOC) of $6.9 \mathrm{mg} / \mathrm{L}$ and $\mathrm{UV}_{254}$ of $0.314 \mathrm{~cm}^{-1}$ were detected in raw water. UVto-DOC ratio was determined as $4.55 \mathrm{~m}^{-1} / \mathrm{mg} / \mathrm{L}$, which fall within typical range of $4-5 \mathrm{~m}^{-1} / \mathrm{mg} / \mathrm{L}$ reported from other water sources in the literature [13].

\subsection{Water sampling and analyses}

Turbidity and dissolved organic matter removals in floating plastic media pre-filter (PP), biofilter (BF) and GAC units were evaluated. Daily sampling of raw and treated water from all treatment units was carried out during 4 months of continuous experiment

Table 1

Raw water qualities.

\begin{tabular}{lll}
\hline Parameter (unit) & Range & Average (SD) \\
\hline Temperature $\left({ }^{\circ} \mathrm{C}\right)$ & $25.8-31.7$ & $29.1(2.0)$ \\
$\mathrm{pH}(-)$ & $7.41-7.96$ & $7.73(0.10)$ \\
Turbidity $(\mathrm{NTU})$ & $29-51$ & $37.7(4.7)$ \\
Alkalinity $(\mathrm{mg} / \mathrm{L})$ & $85-96$ & $92(2.4)$ \\
Hardness $(\mathrm{mg} / \mathrm{L})$ & $64-110$ & $84(17)$ \\
$\mathrm{DOC}(\mathrm{mg} / \mathrm{L})$ & $5.9-8.7$ & $6.9(0.7)$ \\
$\mathrm{UV}_{254}\left(\mathrm{~cm}^{-1}\right)$ & $0.267-0.397$ & $0.314(0.027)$ \\
Conductivity $(\mu \mathrm{s} / \mathrm{cm})$ & $291-333$ & $307(10)$ \\
\hline
\end{tabular}


and the sampled water were analyzed for $\mathrm{pH}$, turbidity, DOC, $\mathrm{UV}_{254}$. All analyses were performed according to Standard Methods for the Examination of Water and Wastewater [14]. The treated water was also subjected to chlorine demand and THM formation tests in which $\mathrm{NaOCl}$ was added at various doses to the water samples and incubated for $2 \mathrm{~h}$. (for chlorine demand test) and $48 \mathrm{~h}$. (for THM analysis) before subjected to residual chlorine and THM analyses. The sum of THM ratio (sTHM) was calculated according to the following equation.

$s T H M=\frac{C_{\text {CHLO }}}{G V_{\text {CHLO }}}+\frac{C_{\text {DCBM }}}{G V_{\text {DCBM }}}+\frac{C_{\text {DBCM }}}{G V_{\text {DBCM }}}+\frac{C_{\text {BROMO }}}{G V_{\text {BROMO }}}$

where

$\mathrm{C}_{\mathrm{CHLO}}=$ chloroform conc. $(\mu \mathrm{g} / \mathrm{L})$

$C_{\mathrm{BDCM}}=$ dichlorobromomethane conc. $(\mu \mathrm{g} / \mathrm{L})$

$\mathrm{C}_{\mathrm{DBCM}}=$ dibromochloromethane conc. $(\mu \mathrm{g} / \mathrm{L})$

$\mathrm{C}_{\mathrm{BROMO}}=$ bromoform conc. $(\mu \mathrm{g} / \mathrm{L})$

$G V=$ Specific limit for individual THM $(200 \mu \mathrm{g} / \mathrm{L}$ for chloroform, $60 \mu \mathrm{g} / \mathrm{L}$ for DCBM, $100 \mu \mathrm{g} / \mathrm{L}$ for DBCM and $100 \mu \mathrm{g} / \mathrm{L}$ for bromoform)

At the end of experiment, the used GAC was evaluated for the remaining adsorption capacity. One gram of used GAC obtained from mid-depth of experimental column was immersed in 11 of synthetic water containing various humic acid concentrations of 25, 50, 100 and $250 \mathrm{mg} / \mathrm{L}$. The adsorption of humic substances onto the GAC was then allowed to reach equilibrium after which the remaining DOC and $\mathrm{UV}_{254}$ in water were analyzed. The removals of DOC and $\mathrm{UV}_{254}$ of the used GAC were compared to those of new GAC and the differences among them are determined as the adsorbed organic substances during the column experiment. Pre-determined relationship curve between humic concentrations and DOC or $\mathrm{UV}_{254}$ allow the conversion of adsorbed DOC and $\mathrm{UV}_{254}$ to the equivalent adsorbed mass of humic substances. The adsorbed organic substances onto GAC were then compared with total organic removal during the column experiment to determine organic substance removal through biological activities on GAC.

\section{Results and discussion}

\subsection{Particle and dissolved organic matter removal}

Fig. 2 presents the variation of turbidity in raw water and treated water from biological filter and GAC during the experimental period. Where raw water contained turbidity mostly in range of 30-50 NTU, turbidity in treated water from the floating media filter was primarily reduced to 10-30 NTU. Some fluctuations of turbidity level in the treated water were observed as breakthrough of particles took place in the filter and periodical cleanings through backwashing were required. Nevertheless, the performance of filter slightly improved towards in end of experiment with majority of water samples had their turbidity level of less than 20 NTU.

As the water was further treated by biological filter, less than 10 NTU in effluent water was achieved. During the experiment, turbidity level in the treated water had an increasing trend during the first 20 days but gradually decreased afterwards to less than 2 NTU. This variation took place along the maturity of biological filter as the porosity of filter bed is reducing with time due to the accumulation of entrapped particles.

In case of GAC, the effluent had lower turbidity of less than 0.5 NTU with little fluctuation. The GAC unit could be operated without clogging and cleaning requirement throughout the experimental period of 120 days.

Fig. 3 shows the variation of dissolved organic matter concentration in term of $\mathrm{UV}_{254}$ in the system. Raw water had relatively stable $U_{254}$ of $0.27-0.40 \mathrm{~cm}^{-1}$. Significant reduction in $\mathrm{UV}_{254}$ was observed in floating media filter.

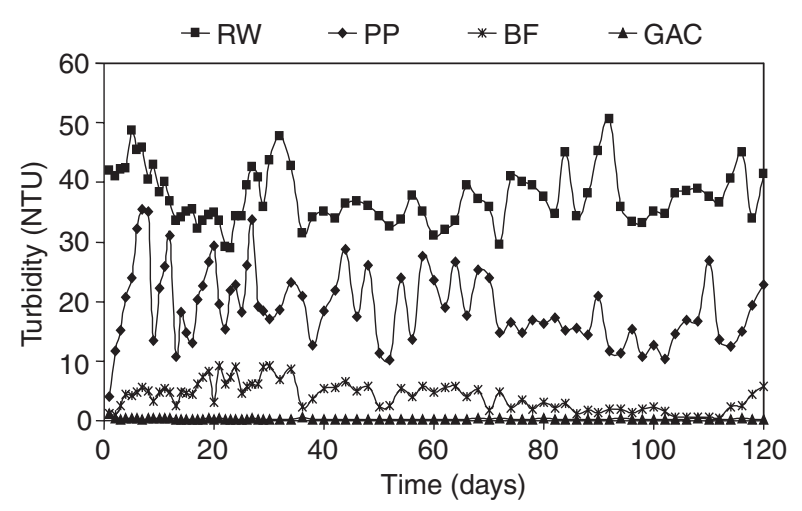

Fig. 2. Turbidity in raw water (RW), floating media filter (PP), biological filter (BF) and GAC.

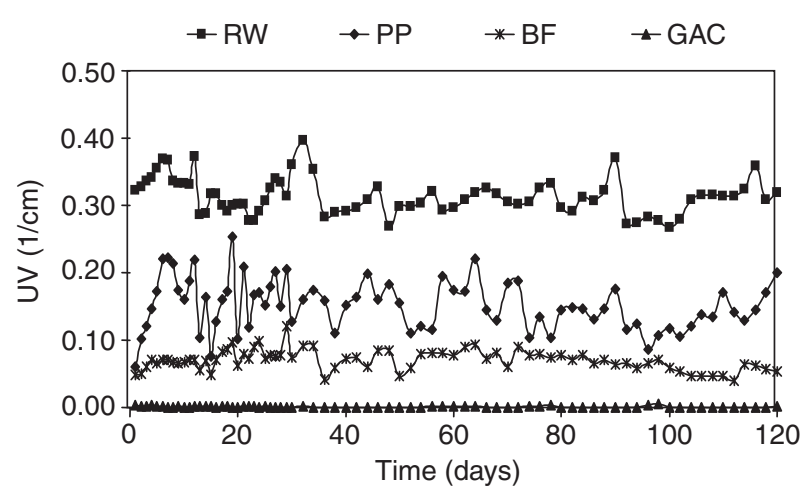

Fig. 3. $\mathrm{UV}_{254}$ in raw water (RW), floating media filter (PP), biological filter (BF) and GAC. 
This was due to the effect of enhanced coagulation [1] as organic matter was adsorbed onto the particles that are subsequently entrapped within the filter bed.

When treated water from floating media filter was fed to biological filter, further reduction of $\mathrm{UV}_{254}$ was observed. The effluent from biological filter contained $\mathrm{UV}_{254}$ of less than $0.1 \mathrm{~cm}^{-1} . \mathrm{UV}_{254}$ was originally low $\left(0.05 \mathrm{~cm}^{-1}\right)$ possibly due to adsorption effect on the media surface at the beginning of experiment and slightly increased to a stable level. After about 60 days of operation, there was a decreasing trend of $\mathrm{UV}_{254}$. Biological activities on the biological filter media could be responsible for this gradual improvement. Even though microbial adaption for humic substance biodegradation may take more than one year [11], some of less biodegradable resistant substances could be removed within shorter period.

It was found that $\mathrm{UV}_{254}$ was almost completely removed in GAC unit. Stable and low level of dissolved organic matter in the effluent was achieved throughout the experiment. Exhaustion of GAC bed was not reached during 120 days of operation so GAC regeneration was not performed.

Table 2 presents turbidity, $\mathrm{UV}_{254}$ and DOC concentration in treated water and their removal in floating media filter, biological filter and GAC units. In overall, floating media filter in combination with GAC had excellent turbidity and dissolved organic matter removals whereas moderate removals were obtained in floating media filter and biofilter units.

\subsection{Reduction in chlorine demand and THM formation}

The removal of dissolved organic matter from raw water also helped reducing chlorine demand and the potential of disinfectant by product formation. Thus, chlorine demand and THM formation in treated water from the system was studied and compared with that of raw water. It was found that raw water samples had chlorine demand of $3.5 \mathrm{mg} / \mathrm{L}$ to produce free residual chlorine of $0.5 \mathrm{mg} / \mathrm{L}$. The treated water from floating media filter, biological filter and GAC units had chlorine demand of $3.0,3.0$ and $2.5 \mathrm{mg} / \mathrm{L}$ respectively. As a result, reduction in chlorine demand of $0.5-1.0 \mathrm{mg} / \mathrm{L}$ or $14-29 \%$ was achieved after removing dissolved organic matter from the water by biological filter and GAC respectively.

Table 3 shows the results from the examination of THM formation in raw and treated water. As chlorine dose was varied at 2.0, 2.5, 3.0, 3.5 and $5.0 \mathrm{mg} / \mathrm{L}$, sum of THM ratio in raw water was determined as $0.5,0.8,0.8$, 0.9 and 1.1 whereas those of treated water from floating media filter were $0.2,0.3,0.5,0.5$ and 0.6 respectively. This is equivalent to $37.5-60 \%$ reduction in THM formation, which is in good agreement with about $50 \%$ dissolved organic matter reduction efficiency achieved in floating media filter unit. Even though THM formation in raw water without any treatment could still comply with WHO guidelines (sum of THMs $<1$ ) in most cases except at $5.0 \mathrm{mg} / \mathrm{L}$ chlorine dose, significant reduction of THM formation in the treated water was achieved through dissolved organic matter removal in the system.

When the water was subsequently treated by biological filter, sum of THM ratio was found to be $0.3,0.4$, $0.5,0.5$ and 0.5 at chlorine dose of 2.0, 2.5, 3.0, 3.5 and $5.0 \mathrm{mg} / \mathrm{L}$. Insignificant reduction in THM formation was achieved in comparison with floating media filter even though about $50 \%$ of reductions in $\mathrm{UV}_{254}$ and DOC were observed in this treatment unit. On the other hand, the sum of THM ratio was significantly reduced to $0,0.1$, $0.1,0.1$ and 0.1 in GAC unit where more than $99 \%$ of dissolved organic matter was removed. These results suggest that GAC performance was much superior to biological filter in terms of dissolved organic matter removal. Nevertheless, both treatment units provided sufficient removal to meet $\mathrm{WHO}$ guidelines for THM at all chlorine doses.

\subsection{Evaluation of GAC adsorption capacity}

After the experiment, the used GAC was examined for its remaining adsorption capacity. Table 4 show the results obtained from batch adsorption test using new and used GAC. The differences in remaining $\mathrm{UV}_{254}$ and DOC

Table 2

Turbidity and organic removal in plastic media pre-filter (PP), biological filter (BF) and GAC units.

\begin{tabular}{|c|c|c|c|c|c|c|}
\hline \multirow[t]{2}{*}{ Item } & \multicolumn{2}{|c|}{ PP } & \multicolumn{2}{|c|}{$\mathrm{BF}$} & \multicolumn{2}{|c|}{ GAC } \\
\hline & Conc. & $\% \mathrm{R}$ & Conc. & $\% \mathrm{R}$ & Conc. & $\% R$ \\
\hline Turbidity (NTU) & $19.2(6.5)$ & 48.3 & $4.1(2.3)$ & 78.3 & $0.3(0.1)$ & 98.2 \\
\hline UV254 (cm-1) & $0.153(0.04)$ & 51.3 & $0.07(0.02)$ & 52.2 & $0.001(0.001)$ & 99.4 \\
\hline DOC (mg/L) & $3.3(0.9)$ & 51.9 & $1.6(0.3)$ & 50.9 & $0.02(0.03)$ & 99.3 \\
\hline
\end{tabular}

The concentrations are presented as average (SD) value. 
Table 3

THMs formation in raw water (RW) and treated water from floating media filter (PP), biological filter (BF) and GAC units.

\begin{tabular}{llccc}
\hline Sample & $\mathrm{Cl}_{2}$ dose $(\mathrm{mg} / \mathrm{L})$ & $\mathrm{CHLO}(\mu \mathrm{g} / \mathrm{L})$ & $\mathrm{DCBM}(\mu \mathrm{g} / \mathrm{L})$ & $\mathrm{DBCM}(\mu \mathrm{g} / \mathrm{L})$ \\
\hline RW & 2.0 & 70.9 & 6.0 & 0.45 \\
& 2.5 & 138.0 & 9.0 & 0.44 \\
& 3.0 & 129.2 & 9.0 & 0.47 \\
& 3.5 & 144.6 & 9.4 & 0.55 \\
PP & 175.1 & 10.7 & 0.54 \\
& 5.0 & 33.2 & 4.4 & 0.38 \\
& 2.0 & 46.0 & 6.4 & 0.59 \\
& 2.5 & 66.8 & 7.7 & 0.76 \\
BF & 3.0 & 73.3 & 8.1 & 0.74 \\
& 3.5 & 86.4 & 8.5 & 0.70 \\
& 5.0 & 33.4 & 5.9 & 0.73 \\
& 2.0 & 52.7 & 8.3 & 0.98 \\
GAC & 2.5 & 60.5 & 8.6 & 0.92 \\
& 3.0 & 67.8 & 9.0 & 0.83 \\
& 3.5 & 70.0 & 9.0 & 0.83 \\
& 5.0 & 1.9 & 1.0 & 0.63 \\
\end{tabular}

Bromoform was not detected in all samples.

Table 4

Adsorption test for new and used GAC.

\begin{tabular}{|c|c|c|c|c|c|c|}
\hline \multirow[t]{2}{*}{ Humic dose (mg/L) } & \multicolumn{3}{|c|}{$\mathrm{UV}_{254}\left(\mathrm{~cm}^{-1}\right)$} & \multicolumn{3}{|c|}{$\mathrm{DOC}(\mathrm{mg} / \mathrm{L})$} \\
\hline & RW & New GAC & Used GAC & RW & New GAC & Used GAC \\
\hline 25 & 0.093 & 0.070 & 0.092 & 2.0 & 1.61 & 2.0 \\
\hline 50 & 0.188 & 0.112 & 0.168 & 3.5 & 2.28 & 3.05 \\
\hline 100 & 0.550 & 0.241 & 0.428 & 9.1 & 3.85 & 7.24 \\
\hline 250 & 1.258 & 0.387 & 0.886 & 15.2 & 5.18 & 11.35 \\
\hline
\end{tabular}

in the solution are used to evaluate the degree of GAC exhaustion. $\mathrm{UV}_{254}$ and DOC concentrations were then converted to humic acid equivalence using pre-determined linear relationship. From the experimental results, it was found that $1 \mathrm{~g}$ of new GAC could absorb $0.39,1.22,5.27$ and $10.05 \mathrm{mg}$ of humic acid at initial humic acid concentration of 25, 50, 100 and $250 \mathrm{mg} / \mathrm{L}$. Meanwhile, the used GAC removed $0,0.45,1.88$ and $3.95 \mathrm{~g}$ of humic acid under the same condition respectively. Therefore, the adsorption capacity of GAC was found to reduce by $60.7-64.3 \%$ after its utilization for 120 days in the experimental system.

The adsorption capacity of GAC that was reduced during the column experiment was determined as $6.1 \mathrm{mg}$ of $\mathrm{C}$ per $\mathrm{g}$ of GAC or $152.5 \mathrm{~g}$ of $\mathrm{C}$ per $25 \mathrm{~kg}$ of GAC in the system. Total DOC removed in GAC unit during 120 days of experiment DOC was calculated as $753.1 \mathrm{~g}$. Therefore, the reduced GAC capacity was accounted only for about $20 \%$ of the removed DOC. This result suggested that biological activities could help reducing large fraction of the adsorbed organic matter on the GAC and thus extending the service time of GAC.

\section{Conclusion}

The following conclusions can be drawn from our study.

1. High removal efficiencies ( $>98 \%$ ) of particle and dissolved organic matter were achieved in floating 
media filter in combination with GAC units whereas moderate removals were obtained in floating media filter and biofilter units.

2. Dissolved organic matter removal in the system resulted in the reduction in chlorine demand by $14 \%$ and $29 \%$ in biological filter and GAC units. Simultaneously, the sum of THMs ratio was reduced from 1.1 to 0.5 and 0.1 respectively.

3. GAC was operated effectively in long-term operation as biological activities helped increasing adsorption capacity of dissolved organic matter and thus extending its service time.

\section{Acknowledgements}

The authors would like to thank Metropolitan Waterworks Authority (MWA) of Thailand for the provision of space and facilities used in this research work.

\section{References}

[1] G. Crozes, P. White and M. Marshall, J. AWWA, 87 (1995) 78-89.

[2] C. Visvanathan, D.R.I.B. Werellagama and R. Ben Aim, J. Environ. Eng.-ASCE, 122 (1996) 25-33.
[3] C. Chiemchaisri, C. Panchawaranon, S. Rutchatanunti, A. Kludpiban, H.H. Ngo and S. Vigneswaran, J. Environ. Sci. Health A, 38 (2003) 2359-2368.

[4] C. Chiemchaisri, W. Chiemchaisri, T. Kornboonraksa, C. Dumrongsukit, S. Threedeach, H.H. Ngo and S. Vigneswaran, Water Sci. Technol., 51 (2005) 93-100.

[5] J.C. Vicker, M.A. Thompson and U.G. Kelkar, Desalination, 102 (1995) 57-61.

[6] C. Chiemchaisri, S. Passananon, H.H. Ngo and S. Vigneswaran, Desalination, 234 (2008) 335-343.

[7] C.C. Chien, C.M. Kao, C.W. Chen, C.D. Dong and C.Y. Wu, Chemosphere, 71 (2008) 1786-1793.

[8] O.D. Basu and P.M. Huck, Water Res., 38 (2004) 655-662.

[9] J.Y. Tian, H. Liang, J. Nan, Y.L. Yang, S.J. You and G.B. Li, Chem. Eng. J., 148 (2009) 296-305.

[10] J. Kim and B. Kang, Water Res., 42 (2008) 145-152.

[11] O.D. Basu and P.M. Huck, Water Sci. Technol.: Water Supply, 4/4 (2004) 147-154.

[12] S. Osterhus, K. Azrague, T. Leiknes and H. Odegaard, Water Sci. Technol., 56/10 (2007) 101-108.

[13] Y. Chang, C.W. Li and M.M. Benjamin, J. AWWA, 89 (1997), 100-113.

[14] APHA, AWWA, WEF, Standard Method for the Examination of Water and Wastewater, 20th edition, Washington DC, 1998. 